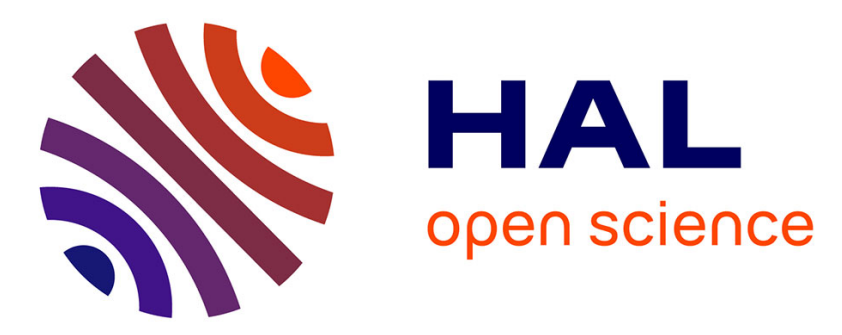

\title{
Assessment of airflow patterns inside six industrial beef carcass chillers
}

Pierre-Sylvain Mirade, Laurent Picgirard

\section{To cite this version:}

Pierre-Sylvain Mirade, Laurent Picgirard. Assessment of airflow patterns inside six industrial beef carcass chillers. International Journal of Food Science and Technology, 2001, 36 (5), pp.463-475. 10.1046/j.1365-2621.2001.00488.x . hal-02682907

\section{HAL Id: hal-02682907 https: / hal.inrae.fr/hal-02682907}

Submitted on 1 Jun 2020

HAL is a multi-disciplinary open access archive for the deposit and dissemination of scientific research documents, whether they are published or not. The documents may come from teaching and research institutions in France or abroad, or from public or private research centers.
L'archive ouverte pluridisciplinaire HAL, est destinée au dépôt et à la diffusion de documents scientifiques de niveau recherche, publiés ou non, émanant des établissements d'enseignement et de recherche français ou étrangers, des laboratoires publics ou privés. 


\title{
Assessment of airflow patterns inside six industrial beef carcass chillers
}

\author{
Pierre-Sylvain Mirade ${ }^{1} *$ \& Laurent Picgirard ${ }^{2}$ \\ 1 Unité Station de Recherches sur la Viande, Equipe Génie des Procédés, Institut National de la Recherche Agronomique, \\ Theix, St Genès Champanelle, France \\ 2 Association pour le Développement de l'Institut de la Viande, Clermont-Ferrand, France
}

(Received 1 December 1999; Accepted in revised form 19 September 2000)

\begin{abstract}
Summary Airflow patterns determine process efficiency in beef carcass chilling. An experimental study of air velocity in six industrial chillers (three batch and three continuous systems) afforded a diagnosis of their overall operation. However, the original experimental method did not provide an ideal chiller design: only configurations that were a priori more favourable for carcass chilling than others were identified. To complete the study, calculations were performed using computational fluid dynamics techniques. Applied to a continuous beef carcass chiller, this helped correct a dysfunction revealed in the experimental diagnosis, resulting in a marked lack of ventilation throughout about half the volume of the plant.
\end{abstract}

Keywords Air velocity, batch chiller, computational fluid dynamics, continuous chiller, plant operation.

\section{Introduction}

Controlling airflow inside industrial beef carcass chillers is of paramount importance because it determines both the efficiency and the homogeneity of carcass chilling.

The plants used to chill beef carcasses are either batch or continuous systems:

1 In batch chillers, the spatial heterogeneity of the air velocity is the main source of variation in chilling time because beef carcasses, especially large ones, placed in low velocity areas will cool far slower than those in high air velocity areas. If all have to be cooled to $7^{\circ} \mathrm{C}$ to meet European legislation then chilling times have to be extended. Wooton (1986) studied the relative effect of various parameters on deep leg temperature in beef carcasses cooled in a conventional industrial batch chiller. The temperatures reached $24 \mathrm{~h}$ after slaughter ranged from 7 to $18{ }^{\circ} \mathrm{C}$. A multivariate analysis showed

*Correspondent: Fax: + 33 (0)473624610;

e-mail: mirade@clermont.inra.fr that carcass location in the room was as important as carcass weight. These two parameters, which explained more than $75 \%$ of the variation, were much more important than any of the other factors tested (i.e., fatness, grade and time of entry into the plant). According to Drumm et al. (1992), the carcasses on the rows nearest the fans are subjected to higher air velocities and lower air temperatures than those hanging further away from the fans. Moreover, having a batch chiller which is partially full may lead to process control problems; for instance, greater carcass spacing leads to higher air velocities and consequently higher cooling rates. These findings clearly illustrate the consequence of uneven air distribution on the efficiency of batch chillers.

2 In continuous chillers, each beef carcass experiences the same average air velocity. There can be advantages in having a higher air velocity in the area where carcasses enter the chiller so that the surface temperature is reduced quickly. However, plant design is poor if high velocities are found in areas where carcasses do not pass 
through. For example, in an industrial chiller that comprised a 'blowing' part and a 'suction' part separated by a partition wall, Bouton (1992) measured air velocities ranging from 1 to $4.3 \mathrm{~m} \mathrm{~s}^{-1}$ below the partition wall but only $0.3 \mathrm{~m} \mathrm{~s}^{-1}$ around the products located in the middle of the suction part. In another industrial bovine carcass chiller, it was found that air velocities were on average twice as high at the level of the carcasses in the blowing part $\left(1.3 \mathrm{~m} \mathrm{~s}^{-1}\right)$ than in the suction part $\left(0.6 \mathrm{~m} \mathrm{~s}^{-1}\right)$. On the other hand, very high air velocities below the partition wall at 40 and $70 \mathrm{~cm}$ above the ground, and also near the wall opposite the partition wall, have also been identified (Rudelle, 1993). In continuous systems, the existence of poorly ventilated areas is much more harmful to process efficiency than airflow heterogeneity because, given their possible large size, they are liable to alter the chilling kinetics strongly and lastingly (Daudin \& Van Gerwen, 1996a).

The work reported here is a part of a scientific programme designed to characterize the overall operation of beef carcass chillers in France (Picgirard \& Mirade, 1998). This work analyses the airflow patterns inside six industrial plants in which a series of measurements of air velocity have been made. The six meat chillers (three batch and three continuous systems) were specially selected as having representative geometry and operation. In addition to these experimental investigations, a study using computational fluid dynamics (CFD) was performed to improve the airflow distribution in a continuous apparatus where measurements had pointed to a lack of ventilation.

\section{Materials and methods}

\section{Measuring the mean air velocity}

In the chillers used in the meat industry, airflows are particularly turbulent and unsteady. Average turbulence rates of $38 \%$ in an industrial beef carcass chiller have been already reported using a hot-wire type anemometer (Daudin \& Kondjoyan, 1991). Air velocities ranging from 0.5 to $15 \mathrm{~m} \mathrm{~s}^{-1}$ have been measured for pork offal, and the higher velocities coincided with the positioning of the measurement system near fans (Daudin et al., 1992).
The difficulties met in the measurement of air velocity in meat plants can be summed up as follows: (i) the presence of blowers and obstacles causes the air direction and velocity to vary rapidly with time, so that their mean values at any one location are difficult to measure, (ii) the mean airflow direction varies in space, and so anemometers that are airflow direction-dependent cannot be used, and (iii) owing to the rapid variations in the mean air velocity in space, known values at one or several points have little meaning, particularly if not averaged over a long timescale (Peyrin et al., 1995; Daudin \& Van Gerwen, 1996b). Hence tests in industrial chillers have revealed that measurements performed with a hotfilm type anemometer at an acquisition frequency of $1 \mathrm{~Hz}$ must be averaged over at least 5 min to obtain a constant value of the mean air velocity (this is called the 'standard average procedure').

As this last procedure is tedious and timeconsuming, a fast, powerful and accurate method for measuring the air velocity by means of a hotfilm type anemometer in an industrial flow was developed (Mirade \& Daudin, 1998a). This method allows the average values of air velocity to be calculated up to several thousand points by the following procedure: (i) probes are moved slowly and continuously, and measurements are recorded at regular intervals, (ii) a signal processing technique is applied to the data to eliminate time-variations because of airflow unsteadiness, as fully as possible, and thus obtain mean air velocity values versus spatial co-ordinates. Using this method the experimental time is shortened 350-fold compared with the standard average procedure, for an accuracy equal to $0.1 \mathrm{~m} \mathrm{~s}^{-1}$, i.e. the measurement error made when using a hotfilm type anemometer.

In continuous chillers, the beef carcass conveyors were used to support and move the multidirectional hot-film type anemometers used (model 8465, TSI, St Paul, Minnesota USA), because of their slow and fairly constant velocity. A purposebuilt cableway-type system was built to move the measurement devices (i.e. anemometers connected to a data logger - Squirrel 1000, Grant, Cambridge, England) inside the batch chillers (Picgirard \& Mirade, 1999). Preliminary tests were performed to find a compromise between a travel velocity high enough to keep the experimental 
time short but low enough to be negligible compared with the air velocity to be measured. A travel velocity of about $1.7 \mathrm{~cm} \mathrm{~s}^{-1}$ was chosen for all the experiments.

\section{Industrial beef carcass chillers}

The industrial chillers studied were selected for their representative geometry and operation. In all, six beef carcass chillers were experimentally characterized: three batch configurations 1A, 1B and $1 \mathrm{C}$ detailed in Fig. 1, and three continuous configurations 2A, 2B and 2C detailed in Fig. 2. Both figures depict vertical sections of the plants.

The first chiller studied, 1A, was for a batch process, with a capacity of 118 beef carcasses (Fig. 1a). 'Carcass' here and elsewhere refers to a side or half carcass. The air conditioning system was located on the left-hand side of the plant. The air flowed in through two blowers located at the top of the eleven rows. At $55 \mathrm{~cm}$ from the floor the air left through two $0.50 \times 1.70 \mathrm{~m}$ extractors.

In the batch chiller 1B (Fig. 1b), the filling capacity was only fifty carcasses. The air conditioning system comprised two cooling batteries and four fans distributed throughout the length of the plant. The air was extracted in the $41 \mathrm{~cm}$ of free space between the air conditioning system and the wall. A jet deflector was installed in front of the system to avoid direct impingement on the metal structures.

Figure 1(c) shows the layout of the batch chiller $1 \mathrm{C}$, which has a capacity of 110 beef carcasses. As in chiller $1 \mathrm{~A}$, the air conditioning system was located on the left-hand side of the plant. The air inflow was from three blowers of surface area $0.5 \mathrm{~m}^{2}$ located just above the rows. A single device extracted the air at $42 \mathrm{~cm}$ from the floor. One of the main characteristics of this batch chiller was that the rows sloped gently and were arranged parallel to the air streams blown in by the three air blowers.

The layout of the first continuous chiller studied is depicted in Fig. 2(a). The carcasses passed along six rows at a velocity of $2.3 \mathrm{~cm} \mathrm{~s}^{-1}$, such that the chilling time was 90 min. Four cooling batteries with sixteen fans spaced regularly along the length of the chiller were used to cool and blow the air around the beef carcasses, and the air was extracted at $180 \mathrm{~cm}$ from the floor through an opening $0.45 \mathrm{~m}$ high.
In the chiller 2B presented in Fig. 2(b), the carcasses passed along eight rows at a velocity of $1.8 \mathrm{~cm} \mathrm{~s}^{-1}$ for $120 \mathrm{~min}$. The air was blown on both sides of five air conditioning systems suspended from the ceiling, and was extracted underneath them.

The last chiller $(17.35 \times 10.6 \times 6 \mathrm{~m})$ was also a continuous process plant (Fig. 2c), where carcasses passed along eight rows at a velocity of $1.25 \mathrm{~cm} \mathrm{~s}^{-1}$ for $140 \mathrm{~min}$. A ninth row was provided in the chiller but was filled only with calf or sheep carcasses. In addition, two cooling batteries and three rows of fans suspended from the ceiling were used to treat and distribute the air in the plant.

\section{Computational fluid dynamics models}

Formerly restricted to nuclear, aeronautic and aerospace industries, CFD techniques have for many years been increasingly applied to other fields and notably to the food industry (Scott \& Richardson, 1997; Mirade \& Daudin, 1998b).

Computational fluid dynamics codes, such as Fluent/UNS (Anonymous, 1996), solve compressible or incompressible fluid flow problems coupled with heat transfer and turbulence phenomena. Fluid motion is governed by mass, momentum (Navier-Stokes' equations) and energy conservation equations (Warsi, 1993). These highly nonlinear differential equations are transformed into algebraic relations using the finite-volume method (Versteeg \& Malalasekera, 1995). Their solution is an iterative process requiring specific algorithms, such as SIMPLE (Patankar \& Spalding, 1972) or PISO (Issa, 1985). To account for the main flow turbulence, turbulence models are used. One of the simplest to use is the $k-\varepsilon$ model (Launder \& Spalding, 1972), where $k$ represents the turbulent kinetic energy and $\varepsilon$, the dissipation rate of $k$. These two quantities are described by complex transport equations that include many empirical coefficients and several constants adjusted from experiments on flat plates and free streams. Hence the $k-\varepsilon$ model is known to perform poorly in a variety of important cases such as unconfined flows or flows with large additional constraints (Versteeg \& Malalasekera, 1995). On the other hand, the flow representation in boundary layers that develop near walls and around objects is 


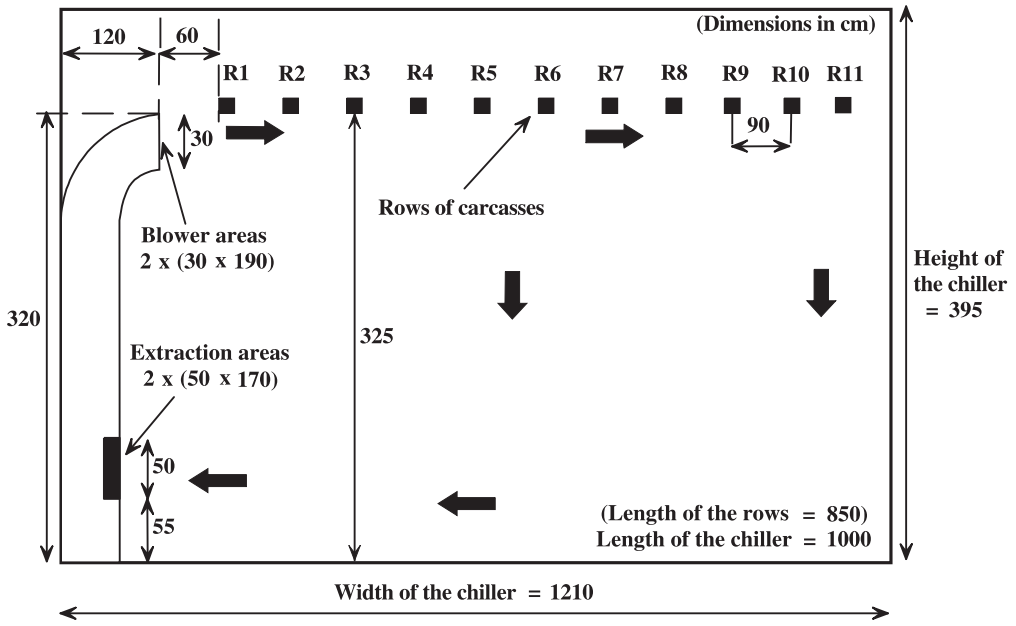

(a)

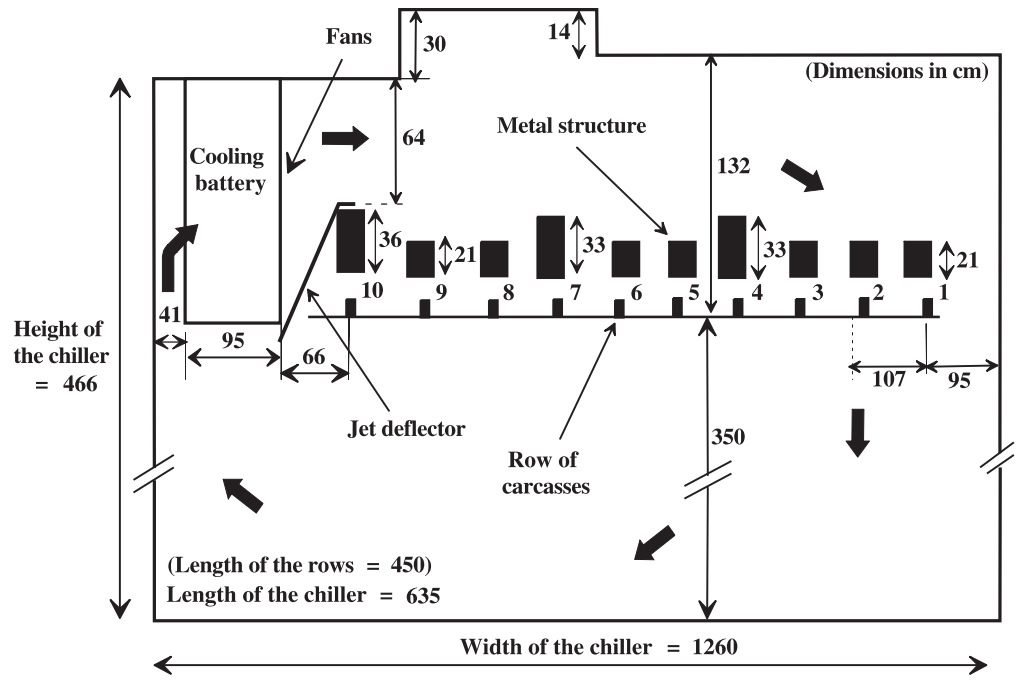

(b)

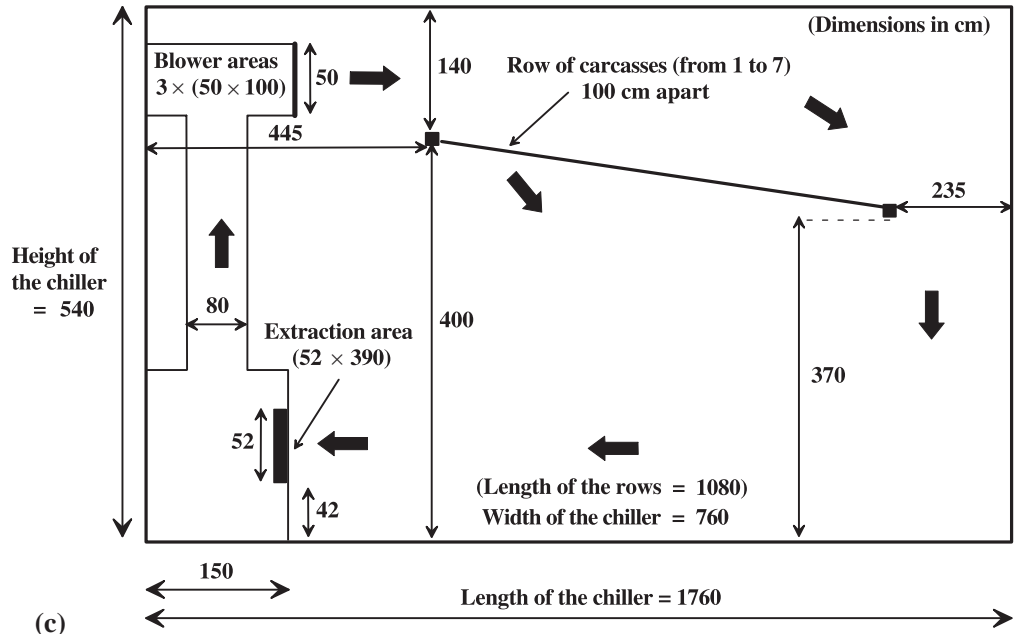

Figure 1 Layout of the industrial batch chillers studied: (a) chiller 1A, (b) chiller $1 \mathrm{~B}$ and (c) chiller $1 \mathrm{C}$. 
Figure 2 Layout of the industrial continuous chillers studied: (a) chiller 2A, (b) chiller 2B and (c) chiller $2 \mathrm{C}$.

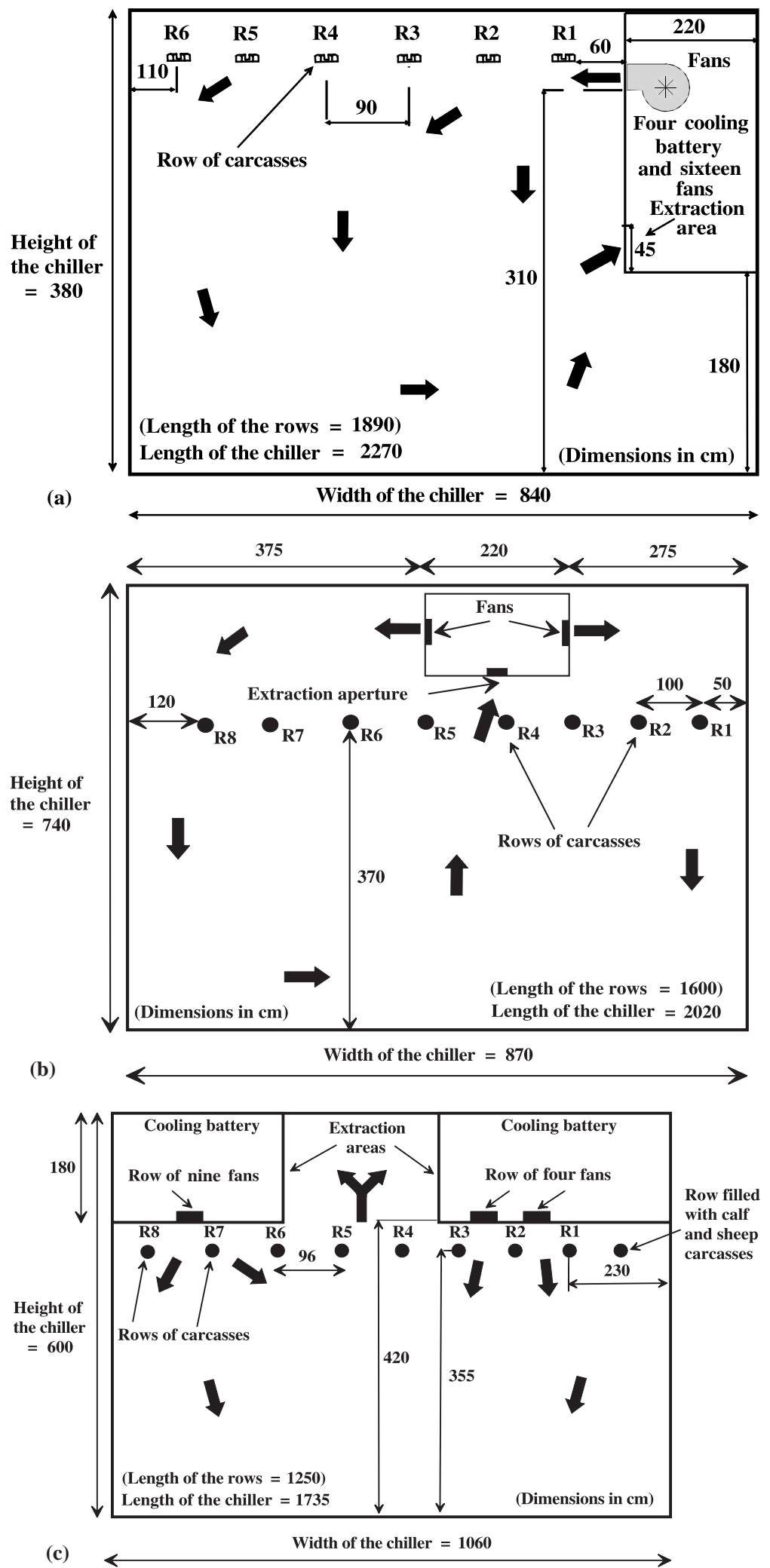

International Journal of Food Science and Technology 2001, 36, 463-475 


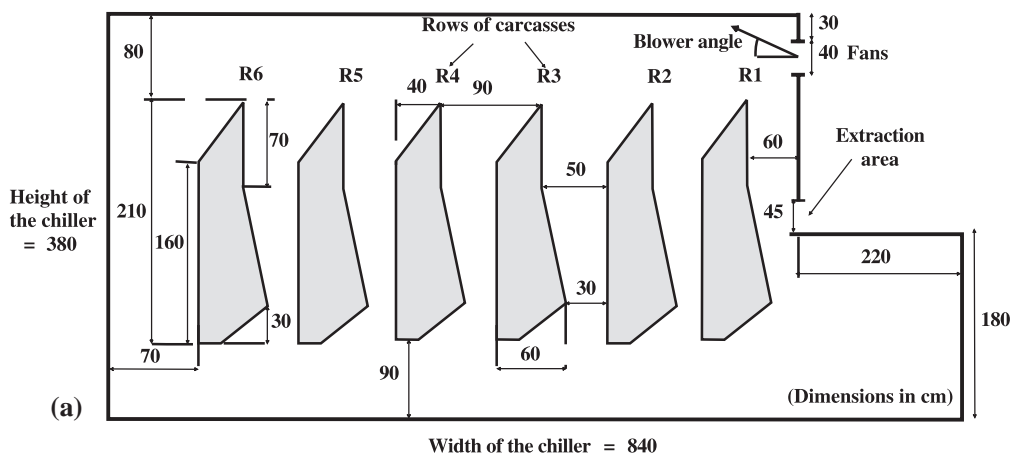

Figure 3 Schematic description of the $2 \mathrm{D}$ numerical model for chiller $2 \mathrm{~A}$. accounted for by specific models such as the 'wall function' which divides, in a simplistic way, the boundary layer into a viscous laminar sublayer and a fully turbulent layer.

The CFD code Fluent/UNS (Anonymous, 1996) was used to simulate the airflow patterns inside the continuous chiller described in Fig. 2(a). An unstructured 2D mesh of 32000 cells, fitting the geometrical configuration presented in Fig. 3, was created. From this mesh, several numerical models were formed, corresponding to the many boundary conditions formulated at the inlet area (three blower airflow rates: the reference blower airflow rate, the reference blower airflow rate increased by $50 \%$ and, by $100 \%$, and three blower angles compared with the horizontal: the reference angle, i.e. $20^{\circ}$, and the reference angle increased by $10^{\circ}$ and, by $25^{\circ}$ ). In all these numerical models, the airflow was considered as steady, incompressible and isothermal. The main flow turbulence was taken into account using the standard $k-\varepsilon$ model (Launder \& Spalding, 1972) far from walls and objects assumed to be smooth and where the standard wall function was applied. The first-order upwind differencing scheme and the SIMPLE algorithm (Patankar \& Spalding, 1972) were chosen. In the inlet area, the magnitudes of the turbulence parameters, $k$ and $\varepsilon$, were also specified, taking the turbulence rate to be $40 \%$ at the outlet of the fans. Calculations were made on a PC (Ppro $200 \mathrm{MHz}$ with $192 \mathrm{Mo}$ of RAM) and the calculation time ranged from 45 to $100 \mathrm{~min}$ depending on the numerical model being solved.

\section{Results and discussion}

To make the results for the assessment of the airflow patterns inside the chillers easier to understand, we paid careful attention to their presentation, for both the measurements and the calculations.

Concerning the experiments, the methodology set up (Mirade \& Daudin, 1998a) allowed rapid acquisition of a large number of measurement points from which air velocity intensity maps corresponding to horizontal, longitudinal and vertical sections of the plant could be plotted. We chose to present histograms giving the distribution of mean air velocities calculated for each height of each row of carcasses.

Like the results of the numerical simulations performed in two dimensions, these were given in terms of mean air velocities calculated from seven profiles located on either side of the six rows of carcasses. The corresponding width distances in the plant were $55,145,235,325,415,505$ and $595 \mathrm{~cm}$, respectively. These profiles were taken from heights where beef carcasses were located, i.e. from 90 to $300 \mathrm{~cm}$.

\section{Experimental results of airflow patterns}

The results for the first batch chiller indicated a fairly heterogeneous airflow (Fig. 4a). High mean air velocities appeared from row 4-8 for a height of $250 \mathrm{~cm}$, reaching a peak of $1.7 \mathrm{~m} \mathrm{~s}^{-1}$ on row 8 . Beyond this row, the mean air velocities decreased and on the last row were only $0.49 \mathrm{~m} \mathrm{~s}^{-1}$ on average (Table 1). This probably resulted from a too-short airflow from the two blower areas. In addition, the histogram in Fig. 4(a) shows mean air velocities approaching $1 \mathrm{~m} \mathrm{~s}^{-1}$ on the first three rows at a height of $100 \mathrm{~cm}$; these high velocities compared with those of the other rows can be attributed to the extraction area located nearby. Essentially, it seems that the air blown by 
Figure 4 Histograms of the distribution of the mean air velocities calculated from measurements for each height of each row of carcasses in the industrial batch chillers: (a) chiller 1A, (b) chiller 1B and (c) chiller 1C.

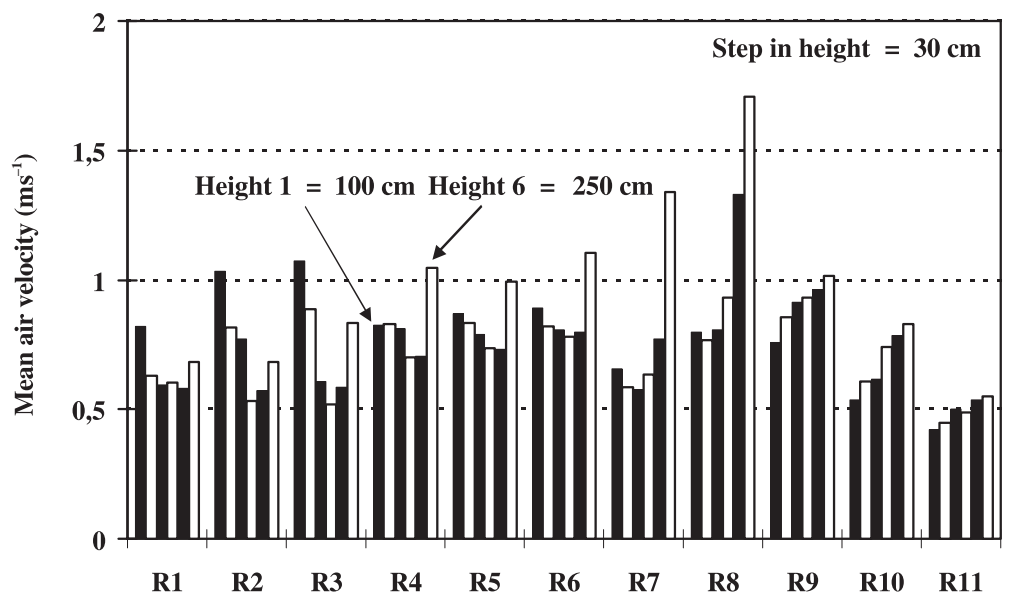

(a)

Row of carcasses
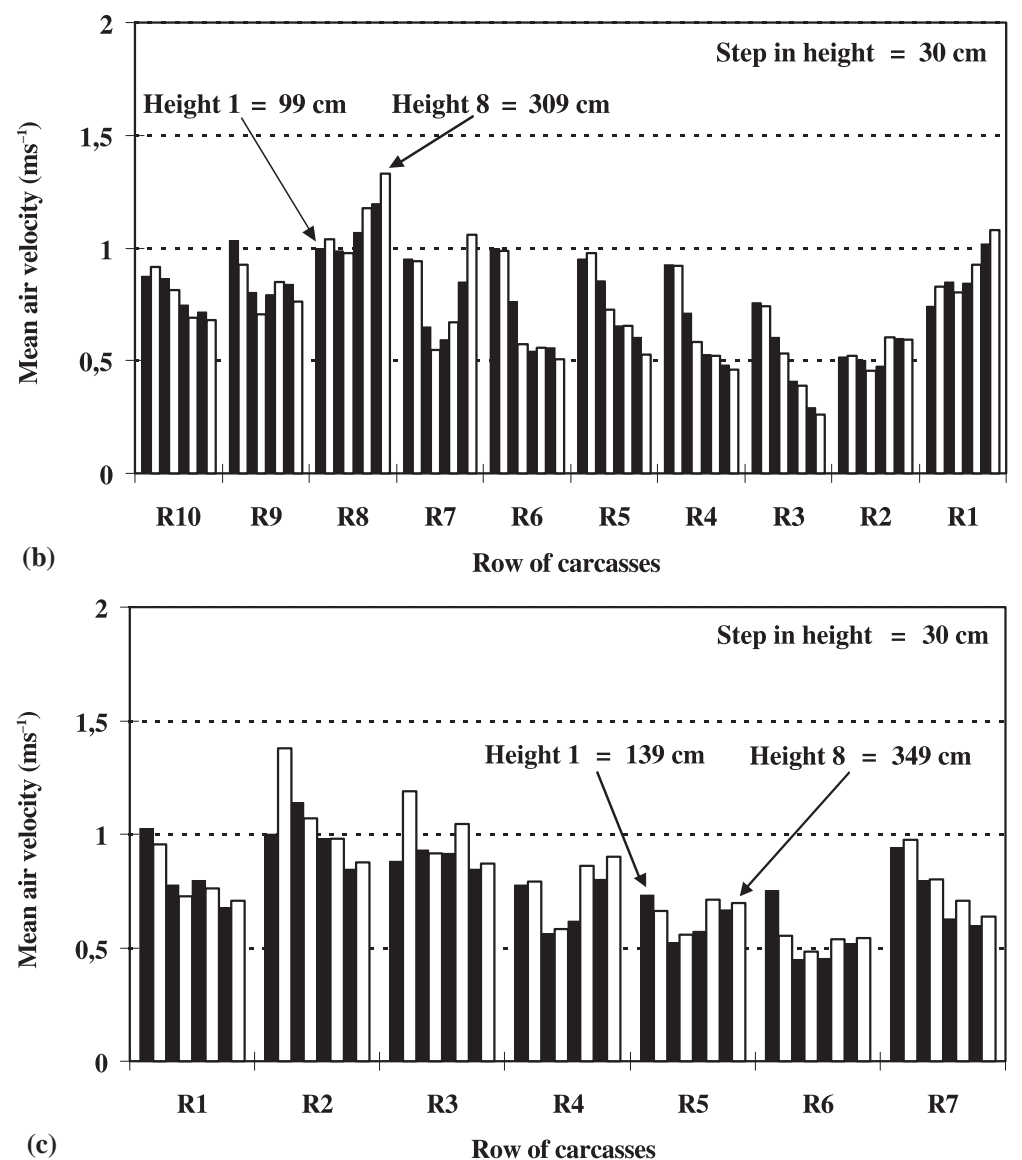

the air conditioning system flows above the carcasses filling the first rows (Fig. 1a), before flowing down around row 8 where the mean velocity is therefore increased by $36 \%$ compared with the overall mean (Table 1). In view of the heterogeneity in the ventilation shown by the histogram, variations in the chilling time can occur between beef carcasses according to their location in this batch chiller. Kondjoyan \& Daudin (1997) calculated that a variation of the air velocity from 
Table 1 Values of mean air velocities $\left(\mathrm{m} \mathrm{s}^{-1}\right)$ calculated from measurements for each row of each chiller

\begin{tabular}{|c|c|c|c|c|c|c|c|c|c|c|c|c|}
\hline \multirow[b]{2}{*}{ Chiller } & \multicolumn{11}{|c|}{ Rows } & \multirow{2}{*}{$\begin{array}{l}\text { Overal } \\
\text { mean }\end{array}$} \\
\hline & 1 & 2 & 3 & 4 & 5 & 6 & 7 & 8 & 9 & 10 & 11 & \\
\hline $1 \mathrm{~A}$ & 0.65 & 0.74 & 0.75 & 0.82 & 0.83 & 0.87 & 0.76 & 1.06 & 0.91 & 0.69 & 0.49 & 0.78 \\
\hline $1 \mathrm{~B}$ & 0.89 & 0.53 & 0.50 & 0.64 & 0.74 & 0.69 & 0.78 & 1.10 & 0.84 & 0.79 & & 0.75 \\
\hline $1 \mathrm{C}$ & 0.80 & 1.03 & 0.95 & 0.74 & 0.64 & 0.54 & 0.76 & & & & & 0.78 \\
\hline $2 \mathrm{~A}$ (full) & 1.60 & 1.18 & 0.72 & 0.42 & 0.37 & 0.27 & & & & & & 0.76 \\
\hline 2A (empty) & 1.50 & 1.41 & 0.96 & 0.68 & 0.58 & 0.52 & & & & & & 0.94 \\
\hline $2 \mathrm{~B}$ & 0.65 & 0.47 & 0.79 & 1.10 & 0.68 & 0.47 & 0.52 & 0.83 & & & & 0.69 \\
\hline $2 C$ & * & 2.55 & 1.73 & 1.67 & 1.38 & 1.38 & 2.09 & 1.65 & & & & 1.78 \\
\hline
\end{tabular}

*Measurements could not be processed.

0.5 to $1.5 \mathrm{~m} \mathrm{~s}^{-1}$ shortened the chilling time by $21 \%$ for a cylinder $0.05 \mathrm{~m}$ in diameter, and by $7 \%$ for a cylinder $0.30 \mathrm{~m}$ in diameter. From data obtained on real beef carcasses, James \& Bailey (1989) arrived at similar conclusions about the effect of air velocity on beef chilling.

Like Fig. 4(a), Fig. 4(b), which represent the variation of the mean air velocity measured in chiller $1 \mathrm{~B}$, shows a heterogeneous airflow that is undeniably responsible for variations in the chilling time among the fifty carcasses filling this plant. In Fig. 4(b), areas more ventilated than others are visible from row 7-10 and on row 1 . The higher mean air velocities ranging from 0.78 to $1.10 \mathrm{~m} \mathrm{~s}^{-1}$ (Table 1) in rows 7-10 can be explained by the fact that the ceiling is recessed overhead (Fig. 1b). The consequence on the airflow patterns of the particular design of this batch chiller is much more obvious in row 8 , where the mean air velocity reached $1.3 \mathrm{~m} \mathrm{~s}^{-1}$ at a height of $309 \mathrm{~cm}$ (Fig. 4b). The big girder located just above row 7 must have also contributed to the high ventilation of row 8 , by deflecting a part of the airflow blown towards it. The high air velocities on row 1 certainly resulted from the presence of a side wall (Fig. 1b). The ventilation troughs on row 3 (values of about 0.3$0.4 \mathrm{~m} \mathrm{~s}^{-1}$ ), for heights ranging from 219 to $309 \mathrm{~cm}$, were a consequence of the big girder overhanging row 4. Consequently, row 2 was not well ventilated either, with a mean air velocity only slightly higher than $0.5 \mathrm{~m} \mathrm{~s}^{-1}$ (Table 1). The chiller 1B is a classic example of a badly designed plant as regards airflow patterns, with the presence of metal structures between the blower areas and the rows of carcasses. Installing a jet deflector in front of the fans did not suffice to prevent airflow heterogeneity in the plant.
As in the two previous chillers, the airflow was heterogeneous in the last batch chiller studied (Fig. 4c), with an imbalance between the left-hand side (from row $1-3$, in which mean air velocities ranged from 0.65 to $1.40 \mathrm{~m} \mathrm{~s}^{-1}$ ) and the righthand side (from row 4-7, where the mean air velocities were all lower than $1 \mathrm{~m} \mathrm{~s}^{-1}$ ). This finding is confirmed by the values in Table 1 . This undoubtedly reveals a dysfunction in the air conditioning system (Fig. 1c), either in the three blower areas or in the extraction area, causing a decrease in the overall mean air velocity (Table 1). Even so, there appeared to be no very marked or recurring variation in mean air velocities with height in the plant (Fig. 4c): this may result from the specific layout of the rows, which sloped gently down and were set parallel to the airflow from the three blower devices, so that the air flowed better between the rows of carcasses. For this reason, chiller 1C has high potential for chilling beef carcasses under batch conditions, once the dysfunction of the air conditioning system is put right.

The histogram for the first continuous beef carcass chiller studied (Fig. 5a) reveals a glaring dysfunction: away from the vicinity of the fans, mean air velocities decreased dramatically. In the main, only the first two rows located near the air conditioning system were well ventilated, with mean air velocities higher than $1 \mathrm{~m} \mathrm{~s}^{-1}$. On the last three rows (rows 4-6), i.e. half of the surface area of the plant, the mean air velocities ranged from 0.27 to $0.42 \mathrm{~m} \mathrm{~s}^{-1}$ (Table 1), thus increasing the chilling time of the carcasses. Hence, for a chilling time of $90 \mathrm{~min}$, the decrease in the temperatures measured at both the core and surface of several carcasses was on average only 2.2 and $8.5^{\circ} \mathrm{C}$, respectively. A possible explanation 

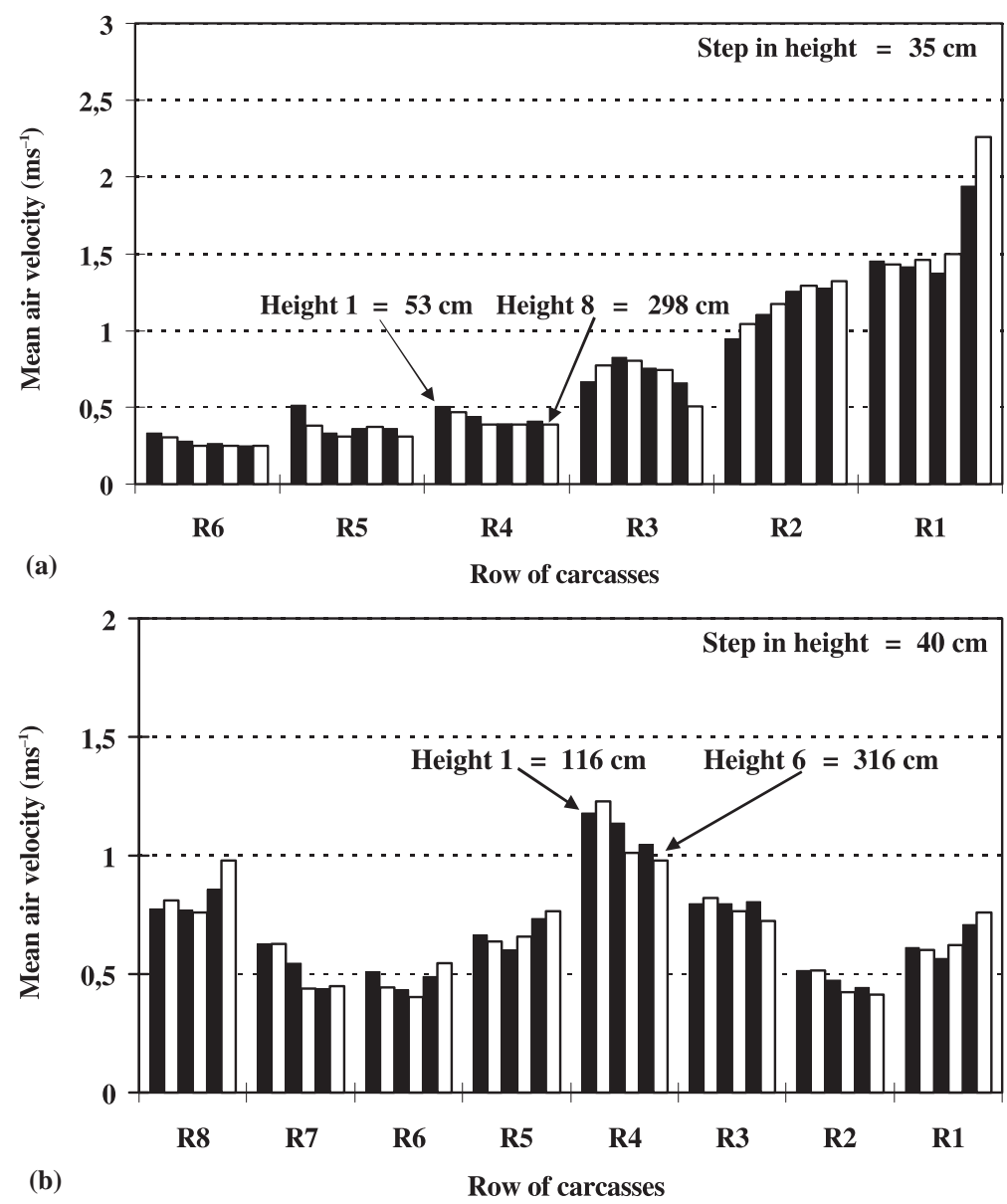

Figure 5 Histograms of the distribution of the mean air velocities calculated from measurements for each height of each row of carcasses in the industrial continuous chillers: (a) chiller 2A, (b) chiller 2B and (c) chiller $2 \mathrm{C}$ (the measurements corresponding to row 1 of chiller $2 \mathrm{C}$ could not be processed).

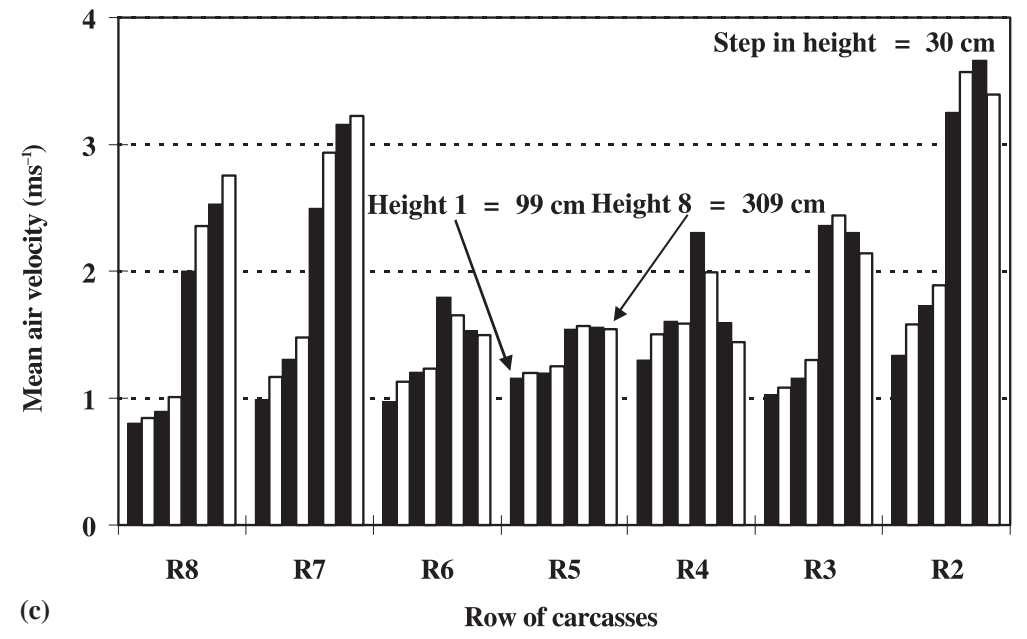

for this dysfunction may be insufficiently powerful fans, or the beef carcasses filling the first rows acting as a barrier to the airflow (Fig. 2a). A further experiment using chiller $2 \mathrm{~A}$ when empty showed that the effect of the carcasses was limited insofar as the whole of the airflow distribution was conserved compared with the results obtained in the full plant: the mean air velocities were 
increased only by about $0.2 \mathrm{~m} \mathrm{~s}^{-1}$ between the two experiments (Table 1). An obvious dysfunction related to the design was therefore discovered by the experimental diagnosis. The results of additional work using computational fluid dynamics techniques, detailed later in this paper, will show how the ventilation around the rows 4-6 can be improved.

For the chiller 2B, Fig. 5(b) shows specific airflow patterns that have already been observed in modern sausage dryers (Mirade et al., 1995). High air velocities were concentrated in the middle (row 4) and on either side (rows 8 and 1) of the chiller. The higher means reaching $1.1 \mathrm{~m} \mathrm{~s}^{-1}$ (Table 1) were located on row 4 , i.e. just underneath the extraction apertures. From the histogram plotted in Fig. 5(b), it seems that the airflow blown on either side of the five air conditioning systems follows the ceiling, then ventilates rows 8 and 1 by flowing down the walls, before being extracted in the middle area. Accordingly, rows 7 , 6 and 2 were the least well ventilated, with mean air velocities of about $0.5 \mathrm{~m} \mathrm{~s}^{-1}$. On the other hand, the homogeneity of the ventilation was fairly good as a function of the height in the same row (Fig. 5b). Nevertheless, the air velocities remained low and the overall mean of $0.69 \mathrm{~m} \mathrm{~s}^{-1}$ was the lowest obtained in all the experiments (Table 1).

Figure 5(c) shows that chiller $2 \mathrm{C}$ was very well ventilated, with an overall mean of $1.78 \mathrm{~m} \mathrm{~s}^{-1}$ (Table 1). It also shows strong variations in the airflow patterns between the upper part (heights ranging from 219 to $309 \mathrm{~cm}$ ) of rows 2, 3, 7 and 8, located underneath the three rows of fans, and the other areas. However, because of the high mean air velocities, the layout of this chiller favours fast chilling of the entering beef carcasses. This is especially so as the higher velocities located in the upper part of the rows are concentrated around the thickest part of the carcasses, which presumably takes the longest to chill.

\section{Numerical results of airflow patterns}

The results of the $2 \mathrm{D}$ simulation inside chiller $2 \mathrm{~A}$ (Fig. 2a) are presented through means of air velocity calculated from seven profiles located on either side of the six rows of carcasses and taken at heights ranging from 90 to $300 \mathrm{~cm}$.

Figure 6 shows the variation of the mean air velocities, calculated from the CFD model and from the measurements, as a function of width in chiller 2A. The location of the comparison points between the two is different insofar as the 2D numerical model allowed only the mean air velocities to be calculated between each row of carcasses, whereas the anemometer measurement system was installed in the location of a beef carcass in each row. Analysis reveals a good agreement between the calculated and measured mean air velocities. In the main, it shows that only the first three rows were correctly ventilated, with mean air velocities higher than $0.7 \mathrm{~m} \mathrm{~s}^{-1}$. For the

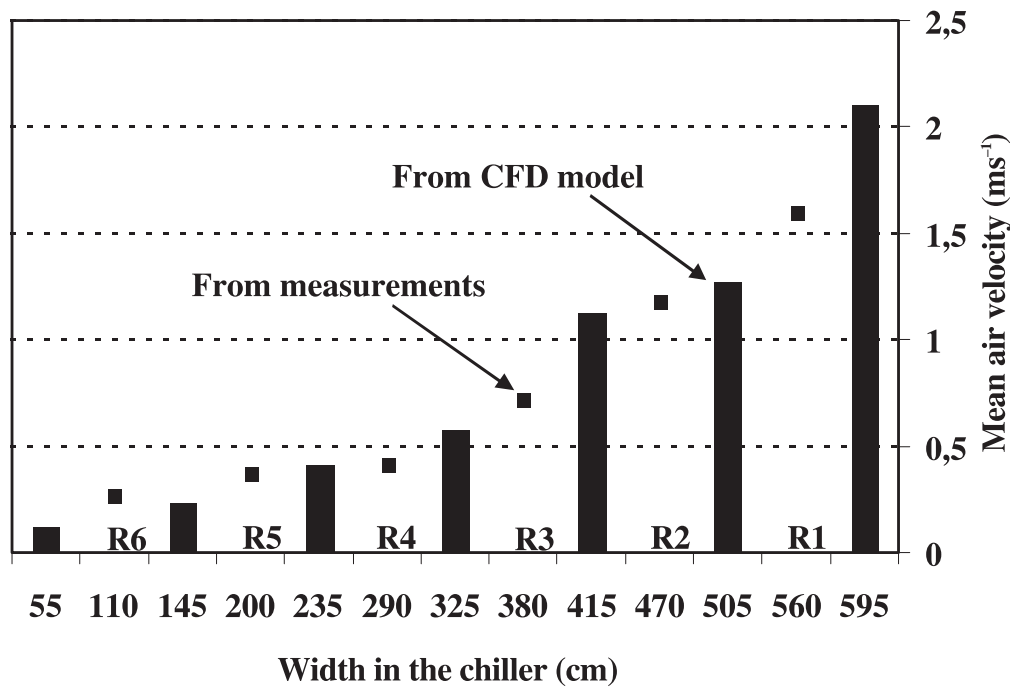

Figure 6 Comparison of calculated and measured mean air velocities inside chiller $2 \mathrm{~A}$. 
three others (rows 4-6), the mean air velocities were lower than $0.5 \mathrm{~m} \mathrm{~s}^{-1}$.

Given its high accuracy in the prediction of the mean air velocities in the reference case (Fig. 6), the CFD code Fluent/UNS (Anonymous, 1996) was used to test some technical solutions for improving the ventilation level around the beef carcasses entering rows 4-6. As shown in Fig. 7(a), increasing the blower airflow rate by 50 or $100 \%$ was insufficient to markedly improve

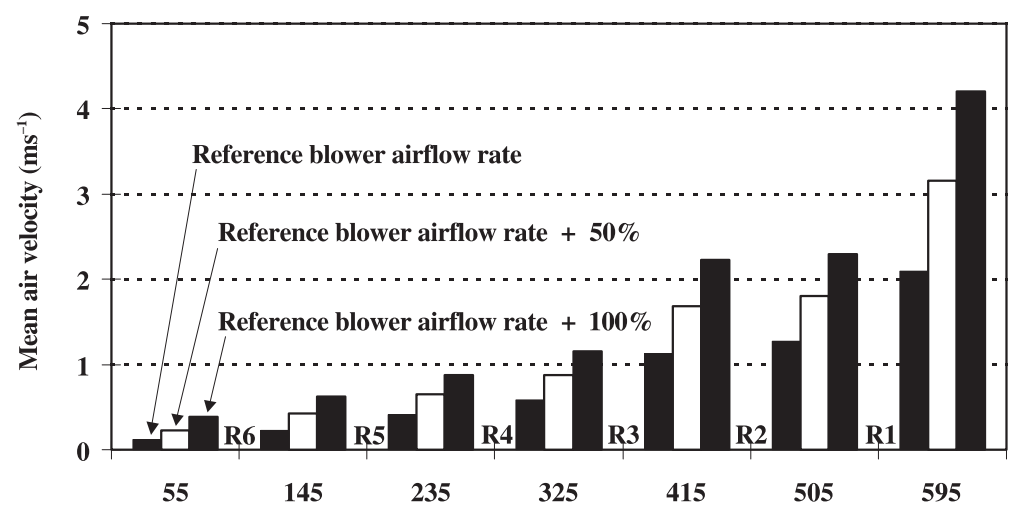

(a)

Width in the chiller $(\mathrm{cm})$

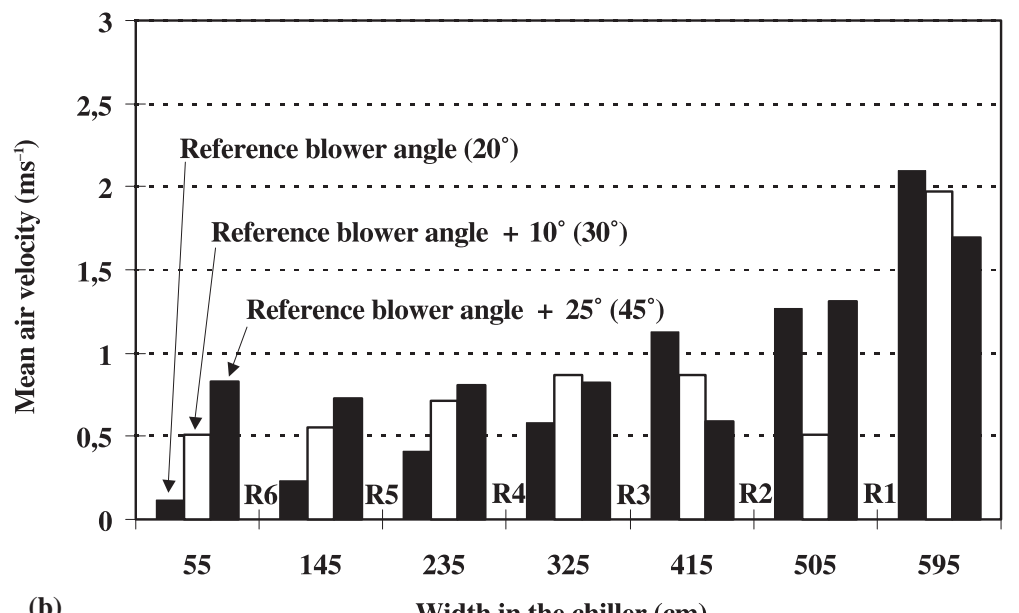

(b)

Width in the chiller $(\mathrm{cm})$

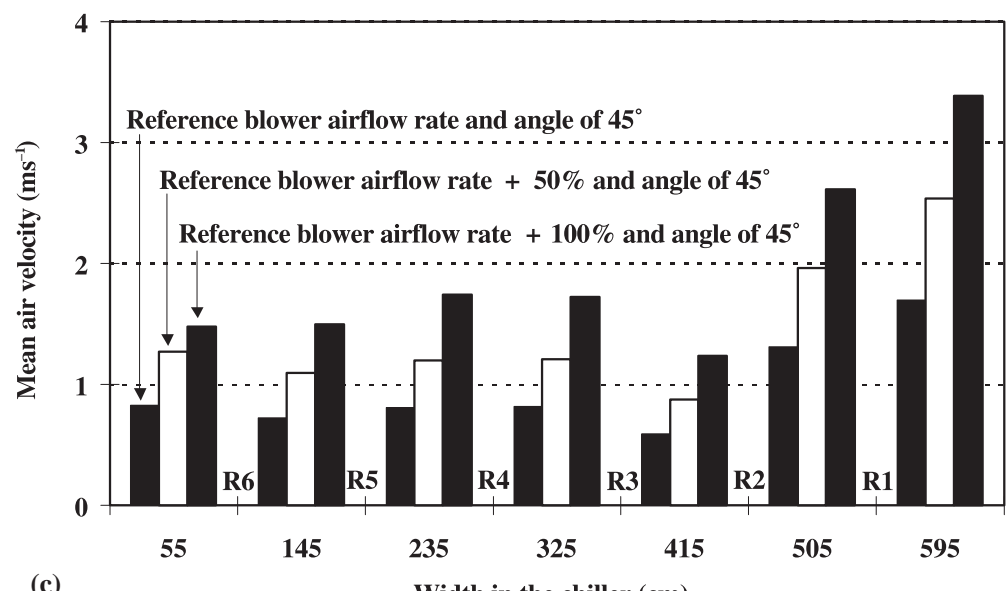

(c)

Width in the chiller $(\mathrm{cm})$

International Journal of Food Science and Technology 2001, 36, 463-475 
the airflow patterns inside the plant; on the contrary, it aggravated the differences in the ventilation between the first rows (rows 1-3) located in the vicinity of the fans and the others (rows 4-6) further from the blowers. Rather than just modifying the blower airflow rate, Fig. 7(b) shows that increasing the blower angle with the horizontal is a better technical solution for making even the air velocities throughout the volume of the chiller. Blower angles of $30^{\circ}$ and $45^{\circ}$ gave mean air velocities higher than $0.5 \mathrm{~m} \mathrm{~s}^{-1}$ around the six rows. A combination of increased blower airflow rate and blower angle (Fig. 7c) helped to ventilate the six rows of carcasses even better, while keeping a satisfactory homogeneity; mean air velocities of about $1.5 \mathrm{~m} \mathrm{~s}^{-1}$ were obtained in the last three rows. This should considerably improve the chilling of the carcasses.

In this example, the CFD tool made it possible to test different technical solutions liable to increase the air velocities around the carcasses. Increasing the blower angle (i.e., installing a jet deflector in front of the fans) is a good compromise between 'efficiency on the airflow patterns' and 'investment costs'; combined with an increased blower airflow rate, the solution is even more efficient, but the cost is higher than before (it may even require changing the air conditioning system).

\section{Conclusions}

This work shows that our experimental method is simple to use and well-suited to processing industrial airflow patterns. The spatial distribution of the measurement points was sufficient to analyse airflows accurately. It affords an explanation of how industrial meat chillers operate and thus reveals dysfunction, such as poorly ventilated areas that impair process efficiency. However, the measurement method set up does not identify an ideal beef carcass chiller design: each configuration suffers from specific disadvantages leading to airflow heterogeneity caused by both the air conditioning system and the chiller geometry. Nevertheless, for the moment, the experiments described can (i) provide plant managers with useful information on the operation of their plant, and (ii) help the professionals in building design and upgrading in slaughterhouses.
This study shows that CFD techniques can be used as a tool for improving air circulation around the carcasses, and thereby process efficiency, although the numerical results require experimental validation. This finding agrees closely with other studies (Scott \& Richardson, 1997; Mirade \& Daudin, 1998b). In addition, further progress can be expected in the future because (i) the calculating power of computers is constantly increasing, but not the cost, and (ii) CFD code is more and more flexible in use. Thus, in few years, it will most probably be possible to fully model how an industrial chiller operates and thus to perform an unsteady numerical study that will accurately simulate the heat and mass exchanges in a plant filled with tens of real meat carcasses.

\section{Acknowledgments}

The authors thank INTERBEV and OFIVAL for their financial support of this scientific programme, and A.T.T. for correcting the English version of this paper.

\section{References}

Anonymous (1996). User's guide for Fluent/UNS \& Rampant. Lebanon: Fluent Inc.

Bouton, V. (1992). Contribution à l'amélioration du fonctionnement et de la conception des installations frigorifiques. Mémoire D'ingénieur de l'Ecole Supérieure Des Ingénieurs et Techniciens Pour l'Agriculture. France: Val de Reuil.

Daudin, J.D. \& Kondjoyan, A. (1991). Influence de l'indice de turbulence de l'écoulement sur les procédés de traitement thermique de solides par l'air, in Récents Progrès en Génie des Procédés (edited by G. Antonini and R. BenAïm) Vol. 5, no. 13, Pp. 287-294. Paris: Lavoisier.

Daudin, J.D. \& Van Gerwen, R.J.M. (1996a). Methods to assess chilling kinetics in industrial chillers, in New Developments in Meat Refrigeration (edited by J.D. Daudin). Pp. Chillers 7-15. Utrecht: EC $\backslash$ CE/AMST-I11.

Daudin, J.D. \& Van Gerwen, R.J.M. (1996b). Air circulation: how to cope with this critical point, in New Developments in Meat Refrigeration (edited by J.D. Daudin). Pp. Chillers 30-37. Utrecht: EC $\backslash$ CE/AMST-I11.

Daudin, J.D., Bouton, V., Prod'Homme, G. \& MourlhonDallies, J.L. (1992). Air flow characteristics in a chiller for pork offals and cooling consequences, in Proceedings of the 38th International Congress of Meat Science and Technology, Vol. 6, 1195-1198. Clermont-Ferrand: ICoMST.

Drumm, B.M., Joseph, R.L. \& McKenna, B.M. (1992). Line chilling of beef 1 : the prediction of temperatures. Journal of Food Engineering, 16, 251-265. 
Issa, R.I. (1985). Solution of the implicitly discretised fluid flow equations by operator-splitting. Journal of Computational Physics, 62, 40-65.

James, S.J. \& Bailey, C. (1989). Process design data for beef chilling. International Journal of Refrigeration, 12, 42-49.

Kondjoyan, A. \& Daudin, J.D. (1997). Optimisation of airflow conditions during the chilling and storage of carcasses and meat products. Journal of Food Engineering, 34, 243-258.

Launder, B.E. \& Spalding, D.B. (1972). Mathematical Models of Turbulence. Pp. 106-107. London and New York: Academic Press.

Mirade, P.S. \& Daudin, J.D. (1998a). A new experimental method for measuring and visualising air flow in large food plants. Journal of Food Engineering, 36, 31-49.

Mirade, P.S. \& Daudin, J.D. (1998b). Numerical simulation and validation of the air velocity field in a meat chiller. International Journal of Applied Science \& Computations, 5, 11-24.

Mirade, P.S., Daudin, J.D. \& Frencia, J.P. (1995). Mesures et modélisation des écoulements d'air dans les installations de réfrigération et de séchage. Viandes et Produits Carnés, 16, 67-73.

Patankar, S.V. \& Spalding, D.B. (1972). A calculation procedure for heat, mass and momentum transfer in three-dimensional parabolic flows. International Journal of Heat and Mass Transfer, 15, 1787-1806.

Peyrin, F., Kondjoyan, A. \& Daudin, J.D. (1995). Analyse des difficultés de mesure de la vitesse de l'air dans les industries agro-alimentaires. Industries Alimentaires et Agricoles, 112, 728-735.

Picgirard, L. \& Mirade, P.S. (1998). Caractérisation des installations de ressuage et de leur comportement aéraulique dans les abattoirs. Rapport Interbev/Ofival, Clermont-Ferrand: ADIV.

Picgirard, L. \& Mirade, P.S. (1999). Installation de ressuage de gros bovins: Vers la maîtrise de l'aéraulique en abattoir. Viandes et Produits Carnés, 20, 123-130.

Rudelle, S. (1993). Contribution à l'amélioration du fonctionnement et de la conception des installations frigorifiques. Mémoire D'ingénieur de l'Ecole Supérieure Des Ingénieurs et Techniciens Pour l'Agriculture, France: Val de Reuil.

Scott, G. \& Richardson, P. (1997). The application of computational fluid dynamics in the food industry. Trends in Food Science \& Technology, 8, 119-124.

Versteeg, H.K. \& Malalasekera, W. (1995). An Introduction to Computational Fluid Dynamics: the Finite Volume Method. Pp. 75, 85-190. Edinburgh: Addison-Wesley Longman Limited.

Warsi, Z.U.A. (1993). Fluid Dynamics: Theoretical and Computational Approaches. Pp. 66-67. Boca Raton: CRC press.

Wooton, A.E. (1986). Factors affecting the chilling rate of beef sides, in Proceedings of the International Institute of Refrigeration, Commission C2, Vol. 3, Pp. 115-121. Bristol: I.I.F/I.I.R. 